\title{
Behavior of Injured Lamina in Lumbar Burst Fractures during Reduction Maneuvers: A Biomechanical Study
}

\author{
Nihat Acar \\ Department of Orthopaedics and Traumatology, Catalca Ilyas Cokay Hospital, Istanbul, Turkey
}

\section{Study Design: An experimental biomechanical study.}

Purpose: This study aims to investigate the behavior of a lamina injury in lumbar burst fractures during reduction maneuvers.

Overview of Literature: Lumbar burst fractures are frequently accompanied by a lamina fracture. Many researchers concluded that any reduction maneuver will close the fractured lamina edges and possibly crush the entrapped neural elements. This conclusion did not rely on solid biomechanical trials and was based primarily on clinical experience.

Methods: Eighteen fresh-frozen lamb spines were randomly divided into three groups. Using the preinjury and the dropped-mass technique, a burst fracture model was developed. A central laminectomy of $5 \mathrm{~mm}$ of the $\mathrm{L} 3$ lumbar spine was created to mimic a complete type of lamina fracture. To measure the movement of the fractured laminar edges, two holes were drilled on both sides of the upper and lower regions of the lamina to allow for optic marker placement. A single specific spine movement was applied to each group: traction, flexion, and extension. Gap changes were measured by camera extensometers.

Results: After traction, the average values of the upper and lower aspects of the lamina interval showed narrowing of $1.65 \pm 0.82$ $\mathrm{mm}$ and $1.97 \pm 1.14 \mathrm{~mm}$, respectively. No statistical significance was detected between the two aspects. The upper and lower regions of the lamina gap behaved differently during extension. At $10^{\circ}, 20^{\circ}$, and $30^{\circ}$, the upper part of the lamina interval was widened by an average of $0.016 \pm 0.024,0.29 \pm 0.32$, and $1.73 \pm 1.45 \mathrm{~mm}$, respectively, whereas the lower part was narrowed by an average of $0.023 \pm 0.012,0.47 \pm 0.038$, and $1.94 \pm 1.46 \mathrm{~mm}$, respectively.

Conclusions: Neural element crushing may take place, particularly at the lower aspect of the fractured lamina gap during extension and throughout the whole lamina gap during traction. The lamina gap widens during flexion. Reduction maneuvers should be attempted after exploring the fractured lamina to prevent further neurological compromise.

Keywords: Burst fracture; Lamina fracture; Biomechanical study

\section{Introduction}

Different lamina injury patterns are encountered frequently in lumbar burst fractures $[1,2]$. Two distinct types of lamina lesions exist: complete and incomplete. A dural tear and nerve root entrapment may accompany lamina fracture; however, it is not possible to verify their existence unequivocally by clinical and radiological methods

Received Jan 7, 2017; Revised Feb 2, 2017; Accepted Feb 17, 2017

Corresponding author: Nihat Acar

Department of Orthopaedics and Traumatology, Catalca Ilyas Cokay Hospital, Catalca 34540, Istanbul, Turkey

Tel: +9-0212-789-19-12, Fax: +9-0212-789-23-71, E-mail: zenanacar@gmail.com 
until surgical exploration [3,4]. Many reports have documented neural element entrapment between fractured lamina edges $[5,6]$. A dural tear and neural entrapment in lumbar burst fractures have been documented in different studies to range from $19 \%$ to $47 \%[7,8]$. One of the goals of surgical treatment of lumbar burst fracture is the restoration of the anatomy of the spinal column, including the spinal canal. In spine surgery, a dorsal midline approach is used to explore the lamina fractures to release any entrapped neural structure, as well as to restore the collapsed anterior and middle spinal columns by applying postural reduction, instrumental angular reduction, and stabilization with segmental transpedicular internal fixation. Both postural and instrumental reductions have important roles in the operative treatment $[9,10]$. Any reduction maneuver of a burst fracture accompanied with a lamina fracture will close the fractured lamina edges and crush the entrapped neural elements. Therefore, when a lamina fracture is present, it is critical to evaluate whether there is any neural entrapment to prevent further neurological impairment [8-10]. To date, the information on reduction maneuvers have not relied on solid biomechanical trials and have been mostly dependent on clinical experience.

The aim of this in vitro biomechanical study is to assess the behavior of fractured lamina edges in lumbar burst fractures during reduction maneuvers.

\section{Materials and Methods}

Eighteen fresh-frozen lamb spines, which were obtained from a local slaughterhouse, were used. This model has a good approximate size and shape to the human vertebrae $[11,12]$. Lamb spine samples were divided randomly to three groups of six. A single specific spine movement, which could be performed during fractured spine reduction trials, was used in each group. In the first group, only axial traction was used. In the second group, only flexion was tested, while extension was tested in the third group. The ages of the lambs were ranged from six to twelve months. The specimens were free of macroscopic and radiological diseases. Spine specimens were dissected from the L1 to the S3 level. All muscle tissues were dissected and cleaned from the spinal segments with care not to harm the interspinous ligaments, ligamentum flavum ligaments, facet joint capsules, and the intervertebral discs (Fig. 1A). Each specimen was wrapped in saline soaked gauze and stored in double plastic bags at $-20^{\circ} \mathrm{C}$.

\section{Burst fracture modeling}

The specimens were thawed in normal saline the night before testing. Upper and lower vertebrae were mounted with white cement and molded into cup shapes. The index vertebra (L3) was weakened using a 1-cm-wide osteotome. The cuts were standardized for all specimens. Using the preinjury and the dropped-mass technique, a burst fracture model was completed in all specimens (Fig. 1B) [13].

\section{Sample preparation}

All samples were prepared by performing a symmetrical central laminectomy of $5 \mathrm{~mm}$ of the L3 lumbar spine to imitate a complete-type lamina fracture. To measure


Fig. 1. (A) Lamb spine sample; the paraspinal muscles were dissected and the interspinous ligament, ligamentum flavum, facet joint capsules, and intervertebral discs were kept intact. (B) Using the preinjury and the dropped-mass technique, a burst fracture model was created in the L3 vertebra. (C) A central laminectomy of $5 \mathrm{~mm}$ was made to mimic a complete lamina fracture. Two upper and two lower holes were drilled on both sides of the lamina to allow for placement of optic markers. (D) Gap changes were measured using a coupled device camera non-contact video extensometer. 
the movement of the fractured lamina edges, two holes were drilled on both sides of the upper and lower parts of the lamina to allow for optic marker placement on both sides to detect any gap interval changes during the spine movements (Fig. 1C). Gap changes were measured and processed using Trapezium 2 data processing software and charge-coupled device camera extensometers (Noncontact Video Extensometer DVE-101/201, Shimadzu, Tokyo, Japan) (Fig. 1D).

\section{Biomechanical testing}

The main purpose of the biomechanical set-up was to measure the lamina gap interval changes during reduction maneuvers, which are primarily composed of traction, extension, and flexion. To perform this task, a Shimadzu Autograph AG-5kNG universal test instrument (Shimad$\mathrm{zu}$ ) was used. In group one, only traction was applied with

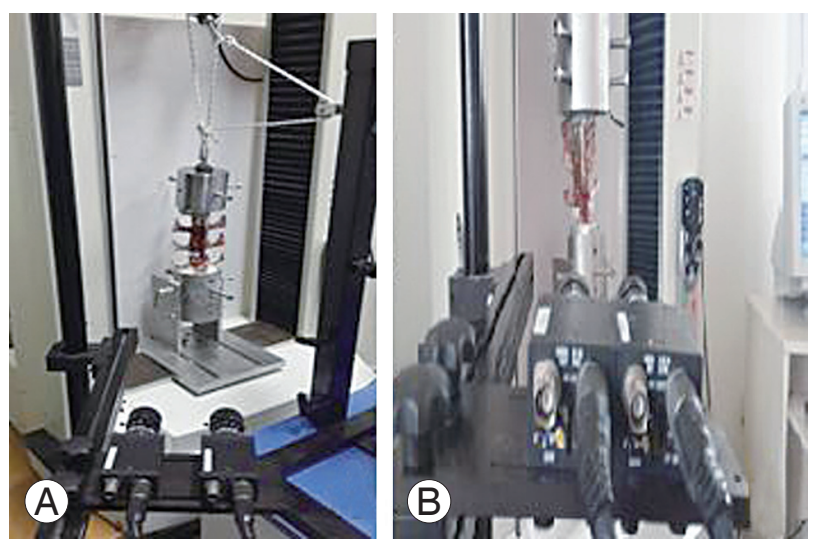

Fig. 2. (A) A custom-made device allowed spine sample flexion and extension up to $45^{\circ}$. (B) The camera system records the optic markers' movement, which is attached to the superior and inferior aspects of the lamina of the fractured vertebra. a constant axial traction of $10 \mathrm{~mm} / \mathrm{min}$ until $30-40 \mathrm{~mm}$ was applied to the specimens, and any changes in the upper and lower gap intervals were recorded. In the second and third groups, flexion and extension movements were used, respectively. To perform flexion and extension, a custom-made apparatus was designed to allow flexion up to $45^{\circ}$ and extension of the examined samples up to $30^{\circ}$ (Fig. 2A).

After setting up the sample, all specimens in groups two and three were subjected to 0-200 N flexion and extension in a displacement-controlled mode, and the custommade apparatus was moved $10^{\circ} / \mathrm{min}$ in flexion and extension. During the forward and backward movements, the upper and lower parts of the lamina gap intervals were recorded using a video extensometer (Fig. 2B) [14]. The camera system recorded the optic markers attached to the superior and inferior aspects of the lamina sides of the fractured vertebrae. For statistical evaluation, a paired $t$-test was used and $p$-value was set to be significant at $<0.05$.

\section{Results}

The lamina gap interval changes related to vertebra traction, flexion, and extension in the three groups are summarized in Table 1. At the end of the applied axial traction, gap interval narrowing was observed. The average gap interval values of narrowing of the upper and lower aspects of the lamina were $1.65 \pm 0.82$ and $1.97 \pm 1.14 \mathrm{~mm}$, respectively. No statistical significance was detected between the upper and lower gap intervals narrowing with $p=0.62$ (Fig. 3). The upper and lower parts of the lamina gap intervals behaved differently during extension. The upper part of the lamina interval widened markedly at dif-

Table 1. The average values of laminar gap interval changes with different spine movements

\begin{tabular}{lccc} 
Type of movement exerted & Upper part of lamina $(\mathrm{mm})$ & Lower part of lamina $(\mathrm{mm})$ & $p$-value \\
\hline Extension $10^{\circ}$ & $(+) 0.016 \pm 0.024$ & $(-) 0.023 \pm 0.012$ & - \\
\hline Extension $20^{\circ}$ & $(+) 0.29 \pm 0.32$ & $(-) 0.47 \pm 0.038$ & - \\
\hline Extension $30^{\circ}$ & $(+) 1.73 \pm 1.45$ & $(-) 1.94 \pm 1.46$ & - \\
\hline Flexion $10^{\circ}$ & $(+) 0.019 \pm 0.023$ & $(+) 0.027 \pm 0.031$ & 0.36 \\
\hline Flexion $20^{\circ}$ & $(+) 0.26 \pm 0.27$ & $(+) 0.48 \pm 0.35$ & 0.18 \\
\hline Flexion $30^{\circ}$ & $(+) 0.89 \pm 0.51$ & $(+) 1.66 \pm 1.12$ & 0.043 \\
\hline Flexion $45^{\circ}$ & $(+) 1.75 \pm 0.96$ & $(+) 2.94 \pm 1.33$ & 0.025 \\
\hline Traction & $(-) 1.65 \pm 0.82$ & $(-) 1.97 \pm 1.14$ & 0.62 \\
\hline
\end{tabular}

$(-)$, demonstrates narrowing of the interval, $(+)$, demonstrates widening of the interval. 
ferent extension degrees. At $10^{\circ}, 20^{\circ}$, and $30^{\circ}$ of extension, the average values of widening of the upper aspect of lam-

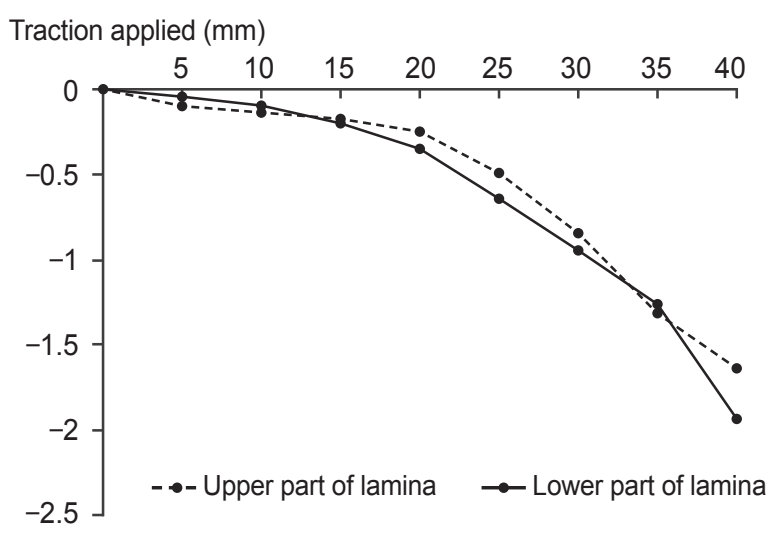

Average of gap interval narrowing $(\mathrm{mm})$

Fig. 3. Upper and lower aspects of lamina gap interval changes after gradual traction application.

Average of gap interval widening $(\mathrm{mm})$

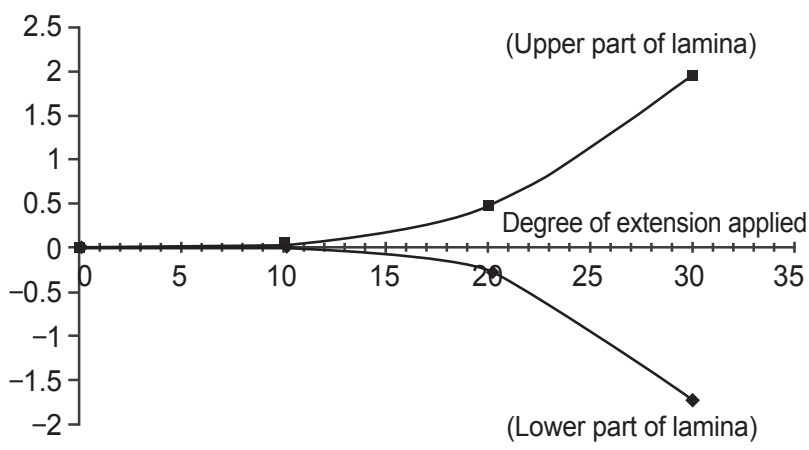

Average of gap interval narrowing $(\mathrm{mm})$

Fig. 4. Upper and lower aspects of lamina gap interval changes after gradual extension application.

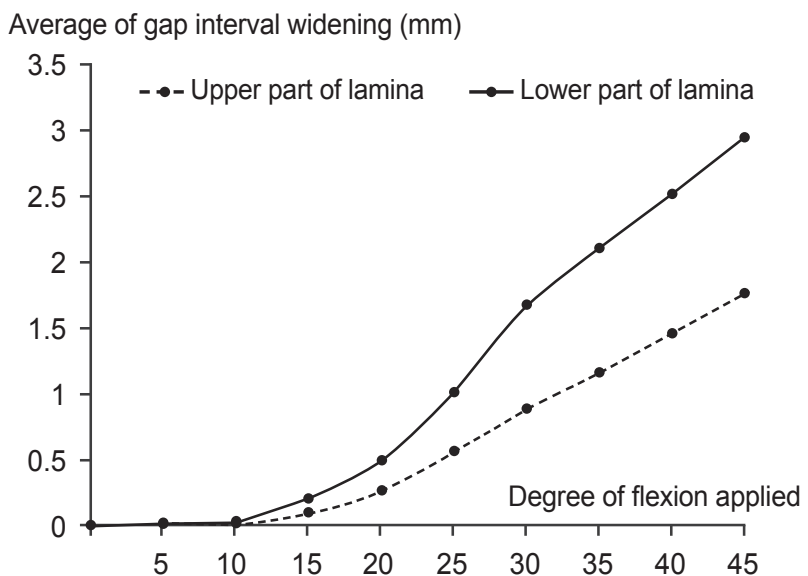

Fig. 5. Upper and lower aspects of lamina gap interval changes after gradual flexion application. ina intervals were $0.016 \pm 0.024,0.29 \pm 0.32$, and $1.73 \pm 1.45$ $\mathrm{mm}$, respectively, whereas the lower aspect of the lamina gap intervals narrowed markedly at the various extension angles. At $10^{\circ}, 20^{\circ}$, and $30^{\circ}$ of extension, the average values for narrowing of lamina intervals were $0.023 \pm 0.012$, $0.47 \pm 0.038$, and $1.94 \pm 1.46 \mathrm{~mm}$, respectively (Fig. 4).

In flexion, the average values of the upper and lower regions of the lamina gap intervals demonstrated widening during different flexion angles. At $10^{\circ}, 20^{\circ}, 30^{\circ}$, and $45^{\circ}$ of flexion, the upper lamina gap intervals average values widened by $0.019 \pm 0.023,0.26 \pm 0.27,0.89 \pm 0.51$, and $1.75 \pm 0.96 \mathrm{~mm}$, respectively. The lower part of the lamina gap intervals average values widened by $0.027 \pm 0.031$, $0.48 \pm 0.35,1.66 \pm 1.12$, and $2.94 \pm 1.33 \mathrm{~mm}$, respectively (Fig. 5). Although both the upper and lower intervals widened during flexion, the lower part of the lamina intervals had statistically significant widening at $30^{\circ}$ and $45^{\circ}$ of flexion, with $p=0.043$ and $p=0.025$, respectively.

\section{Discussion}

Burst fracture is characterized by a failure of the middle column, resulting in a retropulsion of a body fragment into the spinal canal $[15,16]$. Lamina fracture is commonly encountered in burst fractures. Several studies have documented herniation of the neural elements between the fractured lamina edges, which can cause further neurological compromise $[17,18]$. Skiak et al. [8] showed a strong association between the occurrence of a complete lamina fracture and a dural tear. In tears of dura, the likelihood of neural entrapment have been demonstrated at $33 \%$ in complete lamina fractures and $15 \%$ in incomplete lamina fractures. Surgeons are advised to be particularly careful with patients with complete lamina fractures [8].

Some studies have suggested that reduction maneuvers, such as instrumental traction and hyperextension, close the fractured lamina edges on the entrapped neural elements $[19,20]$. Yet, this knowledge is based on clinical and surgical experiences and not on solid biomechanical studies.

There is no literature on biomechanical studies focused on the behavior of fractured lamina in burst fractures during traction, extension, and flexion movements.

The main purpose of this biomechanical study was to assess the behavior of the upper and lower portions of a fractured lamina in a mid-lumbar (L3) burst fracture model during reduction maneuvers. After application of 
the axial traction force, both the upper and lower aspects of the lamina gap interval average values narrowed during the traction exerted. Since traction is one of the main maneuvers used during reduction of the vertebral height intraoperatively $[9,10]$, surgeons should be careful not to damage the entrapped neural elements during traction application. Exploration of the fractured lamina edges to release any entrapped neural element before traction application is advised to prevent neurological impairment, which may be caused by crushing the neural elements by the fractured lamina edges.

During variable degrees of flexion, the upper and lower parts of lamina edges widened. The upper part of the fractured lamina widened significantly more than the lower parts at $30^{\circ}$ and $45^{\circ}$ of flexion (Fig. 6A). During extensional forces, the upper and lower aspects of the lamina intervals performed differently. With a gradual increase in the extension angle, the upper part of the fractured lamina intervals widened, whereas the lower part narrowed (Fig. $6 \mathrm{~B})$.

In the reduction of burst fractures, both postural and instrumental reduction maneuvers play a very important role in the restoration of vertebral height $[10,21,22]$. Lamina injury is considered a severity marker in burst fractures [23]. Several authors recommend a laminectomy for lamina injuries in burst fractures to avoid possible entrapment of the neural element by crushing during reduction maneuvers $[8,10,21]$.

These findings may constitute a guideline for spine
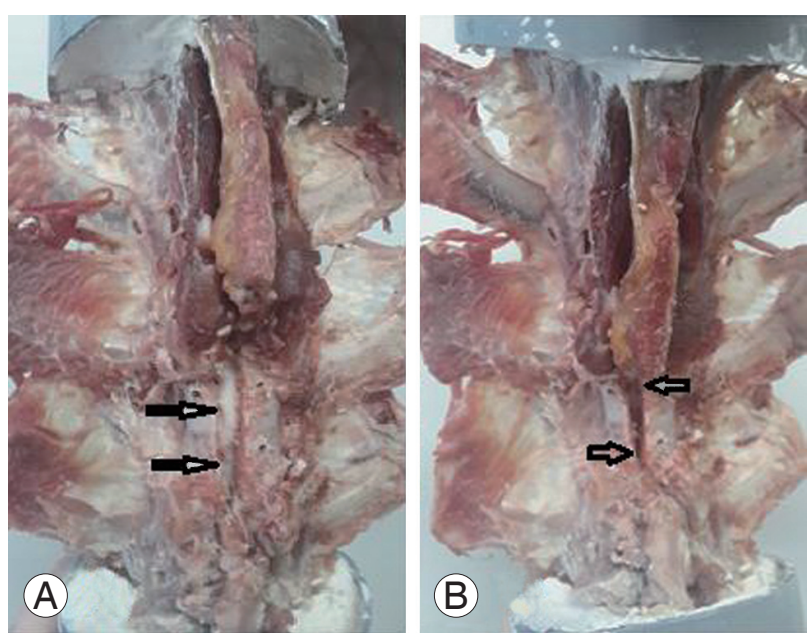

Fig. 6. (A) The upper and lower arrows show the widening of the lamina gap during flexion. (B) The upper arrow shows the widening of the lamina gap, while the lower arrow shows the narrowing of the lamina gap during extension. surgeons to better understand the behavior of a fractured lamina in burst fractures. This study demonstrates that the neural tissue entrapped between fractured lamina edges is in danger when performing reduction maneuvers, such as traction and extension. During these maneuvers, the fractured lamina gap interval, at the upper and lower parts, narrows during traction, whereas it narrows only at the inferior aspect of the fractured lamina during variable extension angles.

This study has some limitations. Lamb spine resembles the human spine in many aspects, but it would be more precise to perform such a trial on human cadavers in the future. Additionally, examining the behavior of a fractured lamina at different thoracolumbar spine levels is recommended.

\section{Conclusions}

In burst fractures accompanied with lamina fractures, neural entrapment may take place, particularly at the lower aspect of the fractured lamina gap during extension and throughout the whole lamina gap during traction. Reduction maneuvers should be attempted only after exploring the fractured lamina to prevent further neurological compromise.

\section{Conflict of Interest}

No potential conflict of interest relevant to this article was reported.

\section{References}

1. Keenen TL, Antony J, Benson DR. Dural tears associated with lumbar burst fractures. J Orthop Trauma 1990;4:243-5.

2. Morris RE, Hasso AN, Thompson JR, Hinshaw DB Jr, Vu LH. Traumatic dural tears: CT diagnosis using metrizamide. Radiology 1984;152:443-6.

3. Pau A, Silvestro C, Carta F. Can lacerations of the thoraco-lumbar dura be predicted on the basis of radiological patterns of the spinal fractures? Acta Neurochir (Wien) 1994;129:186-7.

4. Pickett J, Blumenkopf B. Dural lacerations and thoracolumbar fractures. J Spinal Disord 1989;2:99-103.

5. Fontijne WP, de Klerk LW, Braakman R, et al. CT scan prediction of neurological deficit in thoracolum- 
bar burst fractures. J Bone Joint Surg Br 1992;74:6835.

6. Aydinli U, Karaeminogullari O, Tiskaya K, Ozturk C. Dural tears in lumbar burst fractures with greenstick lamina fractures. Spine (Phila Pa 1976) 2001;26:E4105.

7. Fredrickson BE, Edwards WT, Rauschning W, Bayley JC, Yuan HA. Vertebral burst fractures: an experimental, morphologic, and radiographic study. Spine (Phila Pa 1976) 1992;17:1012-21.

8. Skiak E, Karakasli A, Harb A, Satoglu IS, Basci O, Havitcioglu H. The effect of laminae lesion on thoraco-lumbar fracture reduction. Orthop Traumatol Surg Res 2015;101:489-94.

9. Tropiano P, Huang RC, Louis CA, Poitout DG, Louis RP. Functional and radiographic outcome of thoracolumbar and lumbar burst fractures managed by closed orthopaedic reduction and casting. Spine (Phila Pa 1976) 2003;28:2459-65.

10. Dick W. The "fixateur interne" as a versatile implant for spine surgery. Spine (Phila Pa 1976) 1987;12:882900.

11. Smit TH. The use of a quadruped as an in vivo model for the study of the spine: biomechanical considerations. Eur Spine J 2002;11:137-44.

12. Karakasli A, Sekik E, Karaarslan A, Kizmazoglu C, Havitcioglu H. Are pedicular screws and lateral hook screws more resistant against pullout than conventional spinal hooks and screws in terminal vertebral segment fixation? Eklem Hastalik Cerrahisi 2016;27:22-8.

13. Sekharappa V, Sait A. Simple and economical method to create thoracolumbar burst fracture in a calf spine model. Asian Spine J 2016;10:6-13.

14. Wang H, Li C, Liu T, Zhao WD, Zhou Y. Biomechan- ical efficacy of monoaxial or polyaxial pedicle screw and additional screw insertion at the level of fracture, in lumbar burst fracture: An experimental study. Indian J Orthop 2012;46:395-401.

15. Bridwell KH. Low lumbar (L3-L4-L5) burst fractures. In: Floman Y, Farcy JP, Argenson C, editors. Thoracolumbar spine fracture. New York: Raven; 1993. p.22334.

16. Parker JW, Lane JR, Karaikovic EE, Gaines RW. Successful short-segment instrumentation and fusion for thoracolumbar spine fractures: a consecutive 41/2year series. Spine (Phila Pa 1976) 2000;25:1157-70.

17. Eismont FJ, Green BA. Surgical treatment of spinal injuries: anterior vs. posterior approaches. Adv Orthop Surg 1984;1:24-34.

18. Andreychik DA, Alander DH, Senica KM, Stauffer ES. Burst fractures of the second through fifth lumbar vertebrae: clinical and radiographic results. J Bone Joint Surg Am 1996;78:1156-66.

19. Weinstein JN, Collalto P, Lehmann TR. Thoracolumbar "burst" fractures treated conservatively: a longterm follow-up. Spine (Phila Pa 1976) 1988;13:33-8.

20. Limb D, Shaw DL, Dickson RA. Neurological injury in thoracolumbar burst fractures. J Bone Joint Surg Br 1995;77:774-7.

21. Dick W. Internal fixation of thoracolumbar vertebral burst fractures. In: Burri C, Harder F, Bauer R, editors. Current problems in surgery and orthopedics. 2nd ed. Vol. 2. Bern: Hans Huber; 1987. p.1-137.

22. Miller CA, Dewey RC, Hunt WE. Impaction fracture of the lumbar vertebrae with dural tear. J Neurosurg 1980;53:765-71.

23. Magerl F, Aebi M, Gertzbein SD, Harms J, Nazarian S. A comprehensive classification of thoracic and lumbar injuries. Eur Spine J 1994;3:184-201. 